\title{
LOS RETOS DE LA IDENTIDAD EN LA DIVERSIDAD CULTURAL DE AMÉRICA LATINA. UNA VISIÓN HISTÓRICA ${ }^{1}$
}

\author{
ROBERTO MORA MARTÍNEZ \\ Investigador Centro de Investigaciones sobre América Latina y el Caribe CIALC \\ Universidad Nacional Autónoma de México UNAM
}

\begin{abstract}
RESUMEN
El trabajo aborda los problemas de la identidad en América Latina, ya que actualmente las etnias originarias están luchando por el derecho a un trato justo y diferenciado. Sin embargo, para hablar de la unidad latinoamericana, es necesario plantear la necesidad de olvidar los factores históricos que nos dividen, a través de una asimilación del pasado. De tal modo que, sólo a través del reconocimiento de las diversas leyes e instituciones de los pueblos originarios, se podrá lograr la una relación respetuosa entre los diversos grupos que habitamos América Latina.
\end{abstract}

Palabras clave: Identidad, Olvido, Asimilación, Organizaciones supranacionales.

\begin{abstract}
This paper refers to latin american identity problems. This subject is directly connected to the organization of different original ethnic groups in order to fight for a fair treatment. However, discussing about latin american unity implies to rule out some historical factors that might divide us. I assert that only if we recognize the ruling system of this originary groups, as well as their institutions, we will be able to build a respectful relationship between latin americans.
\end{abstract}

Key Words: Identity, Oblivion, assimilation, Supranational organizations.

1. Se agradece a la DGAPA-PAPPIT de la UNAM, ya que por su apoyo al proyecto La construcción simbólica del enemigo en el imaginario latinoamericano: orígenes, continuidades y rupturas (IN401216), se pudo concretar el presente artículo. 


\section{Introducción}

El tema de la identidad tiene una doble acepción la individual y la social, por lo que consideramos importante iniciar este trabajo, abordando algunas ideas generales en torno al tema de la identidad, debido a que ello nos brinda la oportunidad de exponer aspectos generales sobre la manera cómo se ha ido construyendo la concepción identitaria de los diversos grupos originarios de América Latina.

También señalamos cómo las identidades en América Latina se conformaron a partir de la conquista llevada a cabo por los españoles, por lo que planteamos la necesidad de olvidar aquellos factores históricos que nos dividen como sociedad, para llevar a cabo una asimilación de nuestro pasado, dejando de lado aquello que ya no somos. Por lo que es necesario señalar que ya no somos, que ya no debemos ser, grupos humanos divididos por diferencias étnicas, religiosas o lingüísticas.

En este orden de ideas, es importante avanzar sobre el racismo y el clasismo imperante en América Latina, por lo que es importante exponer la acuerdos de organización supranacional que se están llevando a cabo en Sudamérica, ya que son luchas que exigen un trato justo pero diferenciado. Esto es, la lucha por el respeto de las diversas etnias así como por sus sistemas de organización social.

\section{Por qué abordar nuevamente el tema de la identidad}

Un primer aspecto básico a desarrollar con relación al tema de la identidad, es la definición. Por ello se define a la noción de identidad como: La conciencia que una persona y comunidad, incluso una organización social, tiene del conjunto de rasgos o características que permiten distinguirla de otras. Así, los rasgos hereditarios, la historia, las expresiones culturales y la cosmovisión, contribuyen a conformar la percepción que el ser humano se forma de sí mismo, de la población en torno y de las diversas agrupaciones que surgen en una población.

Ahora bien, el conocimiento que se llega a alcanzar mediante el proceso de identificación del ser humano, es gradual y se desarrolla de acuerdo a las distintas etapas de maduración, así como a sus experiencias. Considerando, además, la información a la que tiene acceso, ya sea únicamente en pláticas familiares, cuentos, leyendas o de manera escolarizada.

En este sentido es oportuno apuntar que algunas personas han incrementado su identidad con prácticas culturales gestadas en otros países, lo cual ha generado debates, pues a la imposición forzada, como aconteció en el caso de América Latina, o la inducida, la cual es más actual y que se lleva a cabo, principalmente, por los medios de información masiva, aunque es cierto que no deja de suscitarse cierto grado de control forzado por los intereses económicos y políticos de las grandes potencias, en este caso se adoptan ritos, costumbres, expresiones verbales, vestimentas, etcétera, los cuales han provocado que grandes núcleos de la población se alejen de lo que les es propio, lo cual desde una visión filosó- 
fica se ha considerado como negativo, principalmente en las naciones que históricamente han sido dominadas.

Sin embargo, el mismo fenómeno se considera como positivo cuando otra persona que proviene de los países dominadores, adopta las formas de vida de los pueblos que fueron conquistados e incluso cambia su residencia para vivir con las poblaciones marginadas. En este segundo caso, se indica la importancia de la cosmovisión y lo valioso de la gente, por lo cual gana adherentes a su forma de vida. Empero ambas formas de transmisión cultural deben ser valoradas. Para ello, es necesario iniciar con la exposición del tema.

\section{El problema de la identidad}

Es necesario señalar que para el ser humano es una constante antropológica el encontrar sus coordenadas específicas dentro de la infinidad de los procesos sociales. De tal modo la imperante necesidad de autoconocimiento se ha enfrentado a una doble respuesta:

1) En aceptar la existencia de un destino que se debe de cumplir con base en la personalidad o carácter individual, que a lo largo de la vida debemos descubrir y con esa base llevar a cabo el papel que se vino a cumplir en el mundo.

2) La vida humana como el resultado del azar, por lo que entonces se conforma un determinado carácter o personalidad como respuesta a los sucesos sociales que experimentamos, los cuales son fortuitos. Por lo tanto, es el ser humano quien se debe dotar de un objetivo de vida.
Desafortunadamente no hay respuestas claras sobre la preexistencia $o$ no de un destino. Por lo cual, cada ser humano debe hacerse responsable de su destino.

Ahora bien, para los individuos es importante la postura que se adopte con respecto a la manera como cada quien se concibe en la vida; sin embargo, el mismo grado de importancia tiene para los seres humanos la identidad comunitaria. De hecho, es posible apuntar que la identidad individual, es una expresión de la identidad social, debido a que lengua, religión, ritos e incluso imágenes y en general la cultura, son aspectos que constituyen las ideas de cada persona sobre sí misma.

De tal modo, es necesario señalar que es el aspecto comunitario en el que vamos a profundizar en este trabajo. Sin embargo, éste también presenta una doble problemática, una es histórica y la segunda es del presente:

1) A lo largo del pasado humano, distintos grupos humanos han entrado en contacto por tres medios: a) la guerra, b) contactos comerciales o c) por casualidad debido a migrantes o viajeros. Relaciones con las que se han modificado las concepciones identitarias. De tal modo, que de ser pequeños grupos nómadas se han ido modificando de las más diversas maneras hasta conformar los actuales estados nacionales. Por lo que no es fácil determinar qué es exactamente lo que compone la identidad de una nación.

2) Desdichadamente, las relaciones entre pueblos diferentes han provo- 
cado en América Latina, así como en otras partes del mundo, que grupos humanos sean segregados, a los que no se les respetan o reconocen sus leyes y cultura.

Ahora bien, el hecho de que no se acepte a un número, elevado, de grupos humanos, en América Latina, principalmente no únicamente a los que se denomina como pueblos originarios, se debe a que la historia humana no se detuvo en los Estado-nación, sino que se han formado sistemas internacionales políticos, de productividad, económico-comerciales, que se han agrupado en torno al patrón de un salvaje capitalismo, que está devastando el planeta.

De tal modo, que el capitalismo globalizado ${ }^{2}$ se ha construido con base en un esquema de sobre explotación de la tierra y de acumulación de capitales en pocas manos, por lo que los grupos que no han ingresado a este sistema son excluidos, precisamente por no contribuir. Claro que sin olvidar, los problemas de desprecio étnico y cultural. Problema que se ha agudizado hoy día, debido a que de los seres humanos que migran de su país (por diversas causas, entre ellas principalmente la violencia y la falta de trabajo), han conformado en otros países pueblos que no quieren olvidar su origen cultural, pero que en

2. Es necesario, señalar que en otros trabajos hemos analizado el aspecto del capitalismo y su relación con el liberalismo, por lo que estamos en la posibilidad de señalar que en este trabajo, nos referimos al actual sistema capitalista que, hoy por hoy, está destruyendo el planeta, sin embargo, consideramos importante señalar que no es la única opción que se puede desprender de las concepciones liberales. ocasiones sus costumbres o prácticas sociales no concuerdan con las de la nación en la que se han establecido. Que es de manera obvia lo que ha creado conflictos de convivencia.

Sin embargo, a pesar de las dificultades que cotidianamente se viven en las relaciones entre diversos grupos humanos, es necesario señalar que la convivencia intercultural es posible. Pero, para comprender dicha posibilidad, primero es necesario profundizar en problemas relacionados con la misma creación de una identidad comunitaria, aspecto que es fundamental, para posteriormente explicar el problema de los términos con los cuales se ha abordado la relación entre diversas culturas.

\section{El sentido de la adscripción}

Hemos abordado el tema de la identidad, en sus aspectos individual y comunitario, así como unas breves líneas sobre la negación a la diferencia. Sin embargo, este tema debe de considerar otros puntos de vista, como el expresado por Xavier Etxeberria, quien señaló que cuando se genera una identidad colectiva de un "nosotros", también supone la exclusión de otro grupo en un "ellos". Idea que consideramos base, para expresar el origen de algunos conflictos sociales, no por el hecho de que las culturas son tan diferentes que por sí mismas provoquen los conflictos, sino porque algunos de los contactos entre grupos humanos que a lo largo de la historia se suscitaron, provocaron conflictos que aun hoy día dividen a los miembros nacidos en diferentes grupos. 
Entonces la pregunta formulada por Etxeberria, consiste en saber qué modelos de pertenencia y exclusión pueden ser calificados como humanos, en el sentido de que se constituyan como válidos éticamente. De tal modo, que para abordar esta pregunta es importante reflexionar sobre el sentimiento de adscripción.

La adscripción como sentimiento de formar parte de algún grupo o de ser un agregado, como vimos es una constante humana. Por lo que es la cultura de la población en la que se creció aquella que dota a los individuos de una explicación sobre las permanentes dudas humanas, las cuales van desde el origen del sol o de todo lo que hay en el universo, hasta la respuesta del porqué muere la gente. De tal modo, que es a partir de las explicaciones que se han ido transmitiendo y modificando de generación en generación, las cuales se refuerzan con un estilo de vida, que los seres humanos logran una existencia aceptable.

Sin embargo, el sentimiento de pertenencia de los seres humanos a un grupo cultural, se desarrolla a su máxima expresión cuando se suscitan choques violentos. Esto significa, que es cuando los propios elementos culturales y la vida misma se defienden o son utilizados para atacar a otros seres humanos, que se concreta el sentido de pertenencia a un grupo.

No es nuestra pretensión señalar que la historia humana se ha desarrollado con base en las guerras, aunque éstas efectivamente han sido el factor principal de transformaciones culturales. Sin embargo, no todos los intercambios culturales han sido por esta vía. Sin embargo, lo que nos interesa destacar es que el sentimiento de adscripción por parte de los individuos, es el factor de arraigo, de pertenencia a un grupo humano, que por lo general comienza con el familiar y continúa con el círculo de amigos, vecinos, conocidos, etcétera, lo que incluye un modo de vida, que al verse en riesgo de desaparición se vuelve más valioso, por el hecho de que es ahí en donde los seres humanos encuentran la raíz de su vida, esto es la explicación de su existencia.

En el caso de América Latina, es necesario señalar que remitirse a los sucesos ocurridos después del 12 de octubre de 1492, es invariablemente necesario, debido a que fue a partir de esa fecha que las culturas originarias se vieron enfrentadas a un proceso de conquista que modificó su percepción cultural.

En este sentido, no debemos olvidar que con los españoles se modificó la concepción de religión, la vestimenta, las formas de trabajo a través de la enseñanza de diferentes herramientas y la alimentación. Asimismo, algunos grupos originarios también transformaron su organización política y social. Sin embargo, el cambio a pesar de haber sido brusco y por más violento, no eliminó los patrones culturales de los pobladores, de tal modo que el sentimiento de adscripción los ha llevado a asimilar los diversos aportes culturales con los que han tenido contacto. Por lo que afirman con orgullo, sobre todo hoy día, su carácter de pueblos originarios. 
¿La unidad por el sentimiento de adscripción?

En la actualidad, como respuesta al proceso globalizador en el que hay una tendencia a querer homogenizar la cultura del mundo, la adscripción ha servido para reafirmar lo valioso de la diversidad cultural.

De tal modo, que las luchas de un número considerable de seres humanos obedece a la búsqueda de fortalecer a los grupos que habían formado parte de un núcleo cultural. Poblaciones que se vieron divididas primero por la conquista y después por la invención de naciones en la época de la independencia separaron pueblos con un origen común. Como ejemplo podemos indicar el caso de los mayas de México y de Guatemala, sin olvidar a los grupos originarios del norte que después de las invasiones norteamericanas quedaron divididos entre México y Arizona como fue el caso de los Yaquis, así como los Pápagos que habitan en Sonora y Estados Unidos. Por otra parte, los grupos andinos quedaron divididos entre Perú, Bolivia, Chile y Argentina.

Además, ese proceso de creación de naciones unió a otros pueblos con procesos históricos diferentes. Por lo que los nacientes países tuvieron que crear nuevas identidades, así apareció lo peruano, lo argentino, lo mexicano, lo guatemalteco. Por lo que precisamente, hasta el momento, el fracaso de las nuevas identidades es que se impusieron estereotipos culturales de una región, la central o capital, sobre las otras.
De tal modo, que a esa nueva identidad nacional se le ha ido dotando en primer lugar de imposiciones simbólicas como los himnos y banderas nacionales, que es cierto que en algunos casos son producto de la historia de un grupo específico, como es el caso del escudo nacional mexicano que proviene de la historia de los mexicas, por lo que se dejaron de lado otras tradiciones de los diversos pueblos originarios que también habitan en México. A pesar de que puede considerarse como un rescate del pasado indígena, resultó una imposición.

El resultado histórico, fue que al fundar los nuevos países se reunieron a diversos grupos culturales al mismo tiempo que se dividió a otros que pertenecían al mismo tronco. De tal manera que, es oportuno señalar que hubo la necesidad de crear nuevas identidades que nunca estuvieron bien definidas y que fueron impuestas. Por lo que no se conformó ninguna nación.

En este punto consideramos oportuno detenernos para expresar algunas reflexiones en torno al tema de la nación, ya que coincidimos con las ideas que en el siglo XIX, expresó Ernest Renán, sobre la manera cómo se puede concebir la creación de una nación en el sentido moderno.

\section{¿La unidad nacional por miedo del olvido?}

Ahora bien, queremos iniciar este acápite citando una idea que nos parece interesante del trabajo de Ernest Renan (1987), en la que afirma que "una nación [...] representa una antigua 
conquista aceptada primero y olvidada después por la masa del pueblo" (p. 63).

Esta idea que nos parece interesante, a pesar de que parece ir en contra de las actuales demandas de los grupos originarios, ya que en el pasado jamás fueron incorporados a los proyectos de una nación; por lo que estamos discutiendo el tema de la diversidad cultural. Por lo que es necesario dejar en claro, que se trata de olvidar aquello que nos divide, que nos enfrenta, por lo que no se trata de dejar de lado aspectos como las matanzas estudiantiles y en general atropellos contra la sociedad, ya que tener presente este tipo de atropellos permite crear conciencia en la sociedad.

Es importante afirmar que esa necesidad de olvido, desde nuestra perspectiva no la concebimos como la omisión o abandono de los acontecimientos de la historia, sino como la asimilación apuntada por Leopoldo Zea, quien basándose en Hegel, señaló que seremos capaces de asimilar nuestro pasado, cuando seamos capaces de negar lo que ya no nos es propio dentro de una lógica dialéctica, por lo que "negar no significa eliminar sino asimilar, esto es, conservar. De acuerdo con esta lógica lo que se es, se es plenamente, para no tener necesidad de volver a serlo" (Zea, 1976, p. 52).

Para explicar qué es una nación en el sentido moderno, Renan señaló que en la historia de la humanidad los pequeños grupos humanos de los inicios de la humanidad, eran por lo general familias que se fueron integrando hasta conformar las grandes ciudades de la antigüedad de miles de personas y de allí se pasó a constituir las naciones de hoy que cuentan con millones de seres humanos.

Han sido diversos los factores con los cuales se ha identificado a la nación como específico grupo humano, de tal modo que la lengua, la religión, las fronteras geográficas y sobre todo las concepciones de raza; principios, todos ellos, insuficientes para explicar la conformación de una nación. Por lo que en opinión de Renan, las actuales naciones obedecen más su establecimiento a diversos aspectos como lo fue la dinastía de los Capeto en Francia; por la voluntad de las provincias, como en Holanda y Bélgica o por un espíritu general tardío del feudalismo como en Italia y Alemania.

Renan previamente señaló que las actuales naciones europeas iniciaron con una serie de invasiones violentas, por lo que es de suma importancia destacar que la identificación de raza con el de nación, como criterio más directo, es falso, debido a que las invasiones y la mezcla de razas fue una práctica tan profunda que es casi imposible mantener esa idea. En este sentido, apuntó que "Pese a la extrema violencia de costumbres de los invasores germánicos, el molde que impusieron llegase a ser, con el paso de los siglos, el molde mismo de la nación. 'Francia' se convirtió con toda legitimidad en el nombre de un país donde no había entrado más que una imperceptible minoría de francos" (Renan, 1987, p. 64).

Antes de avanzar, consideramos oportuno detenernos para señalar que sabemos que hoy día existen otras concepciones de la manera cómo en la 
modernidad se caracterizó a la nación, sobre todo vinculándola al Estado, entendido éste como un ordenamiento jurídico, cuya finalidad es la construcción, ejercicio y mantenimiento del poder soberano en un territorio delimitado, al que están subordinados de manera necesaria los individuos que le pertenecen. De tal modo, lo importante del trabajo de Renan es que nos permitió introducir el estudio de la nación y la concepción del olvido para su consolidación.

Con esta base, es posible señalar que en opinión de Renan, la nación moderna se constituye por un principio espiritual, que se conforma de dos partes; una está en el pasado y la otra en el presente. La primera es el rico legado en común de recuerdos. La segunda, es el consentimiento de vivir en conjunto. Así, el culto a los antepasados es la forma más legítima de honrar la historia y fortalecer el actual sentido de vida en sociedad. Así, en el pasado heroico se asienta una idea nacional. "Tener glorias comunes en el pasado, una voluntad común en el presente; haber hecho grandes cosas juntos, querer hacerlas todavía, he aquí las condiciones esenciales para ser un pueblo. Se ama en proporción a los sacrificios soportados, a los males sufridos" (Renan, 1987, p. 84).

De tal modo, que los miembros integrantes de una nación hoy día deben de compartir tres aspectos: a) del pasado una gloria común; b) en el presente retos y fracasos; c) en el porvenir un mismo programa a realizar. Precisamente en este último aspecto deben de dirigirse nuestras reflexiones, ya que en los programas de gobierno de los distintos países de América Latina se han olvidado de construir proyectos de integración de la diversidad.

Por la falta de un programa a realizar en conjunto que beneficie a los diversos grupos humanos, plantear el olvido de los males padecidos por la población, desde la conquista hasta la actualidad, resulta en América Latina como impensable; precisamente por ello, es que los diversos grupos étnicos han buscado fortalecerse a través de establecer alianzas entre ellos y, por lo tanto, distanciándose de los gobiernos nacionales, por lo que el debate sobre las características de las relaciones interculturales, es muy importante.

\section{Qué es una nación}

Ahora bien, aunque el trabajo de Ernest Renan es interesante, es necesario señalar que con el concepto de nación, en realidad se está haciendo referencia a diversas formaciones sociopolíticas.

En este orden de ideas, el concepto aportado por Renan, está haciendo alusión a un sentido moderno del concepto nación; sin embargo, existen otras acepciones que guardan relación con formas de identificación colectiva. Como lo señala Héctor Díaz Polanco "Un grupo humano se constituye como nación cuando sus miembros se reconocen mutua y firmemente en ciertos deberes y derechos en virtud de su común calidad de miembros. Es ese reconocimiento del prójimo como individuo de su clase lo que los convierte en nación, no los demás atributos cualesquiera que puedan ser" (Héctor Díaz Polanco, 
1988, p. 7). Por lo que en su opinión no sólo son factores étnico-culturales, sino también las luchas internas de clases.

Consideramos oportuno recordar que el concepto de etnia está relacionado con el de nación. Sin embargo, la acepción de nación en su sentido étnico, es diferente al concepto de nación en su acepción política. Debido a que esta última se comprende dentro de un marco de instituciones, así como de códigos legales surgidos bajo las ideas rectoras de las tradiciones liberales, federales y republicanas de diversos países de Europa y de los Estados Unidos. Por lo que no se ajustan $\mathrm{y}$ menos aceptan a las instituciones y leyes (llamados en México, usos y costumbres) de grupos originarios. Con lo que se está marcando una diferencia entre los ciudadanos que heredaron los sistemas políticos de organización social prehispánicos, de aquellos que viven en la tradición occidental.

En todo caso, es necesario hacer notar que el sistema político de bases liberales, republicanas y federales que en la mayoría de los países latinoamericanos es el que rige, no acepta otros diferentes, debido a que así se debilitaría su sistema de legitimación. Sólo como un ejemplo, podemos mencionar el caso de las votaciones, debido a que si un gobierno no alcanza un porcentaje razonado de votos, entonces no puede ostentarse como un representante válido de la población.

Así, con base en la necesidad de legitimación del sistema político de corte occidental, es que no es posible aceptar otros sistemas políticos que puedan conducir a transformaciones.
Sobre todo si consideramos que no estamos hablando de uno o dos grupos humanos, sino que en realidad se está abordando una situación compleja, ya que por ejemplo en México, podemos hablar de más de cuatrocientos pueblos originarios, pero no sólo ello, sino que además es necesario reconocer la existencia de agrupaciones o asociaciones diversas, que también están luchando por reconocimiento y establecimiento de diversas leyes, entre ellos los grupos feministas, los lésbico-gay, sin olvidar a las organizaciones en defensa de la ecología, de los animales, en contra del maltrato a las mujeres. Sin olvidar a las comunidades de migrantes, así como a las organizaciones religiosas.

De tal modo, que si se consideran la diversidad de intereses que se pueden gestar en una nación, entonces es obvia la necesidad, de cualquier grupo que esté en el gobierno, de mantener todo bajo control.

Estamos en posibilidad de señalar que el problema de la diversidad cultural, no se puede resolver si no se entiende cómo en las relaciones interculturales se está ejerciendo un ejercicio ético, que ha posibilitado una convivencia entre los diversos grupos humanos que habitamos en América Latina.

\section{El reto identitario}

Es el momento de abordar el reto identitario, que desde nuestro punto de vista exige una breve recuperación de las ideas expuestas. Por lo que en primer lugar es necesario señalar que la búsqueda identitaria es una constante 
humana, a través de la cual encontramos arraigo, tanto en lo individual como en lo comunitario. Sin embargo, esa adscripción grupal, construye un nosotros y un ellos, es decir, se establece la diferencia.

En el caso de América Latina, que desde la época independiente ha pretendido eliminar las diferencias con la intención "buena o mala", "verdadera o falsa" de crear un grupo humano unificado resultó un fracaso, debido a que en los proyectos de construcción nacional, no se los consideró como grupos que también tenían derecho a gozar de la riqueza nacional.

Ahora, debemos aceptar que las identidades nacionales no han conseguido unificar a la diversidad cultural y no hay indicios de que ello pueda ocurrir. No por el hecho de que los grupos originarios no se sientan pertenecientes a una nación, sino por el hecho de que esa nación, cualquiera que sea, los ha marginado. De allí la importancia que hoy día han adquirido las experiencias de integración supranacional. Cuyo ejemplo más reciente son la Comunidad Andina, la Comunidad Centroamericana e incluso, por qué no señalarlo la experiencia del EZLN al integrar a diversas etnias.

\section{Las integraciones supranacionales}

En primer lugar es necesario destacar lo que vamos a entender por supranacionalidad, por lo que citamos las ideas expresadas por Jaime Delgado, quien señala que la supranacionalidad se constituye "por Estados cuya vecindad regional les ha aportado algún proyecto político más o menos compartido y cierto grado de identidad" (Jaime Delgado, 2008, p. 184).

Desde esta perspectiva consiste en una integración resultado de la expresión política de los Estados de fortalecer sus vínculos. Para este trabajo, queremos destacar dos de los más acabados: 1) La Alternativa Bolivariana para los pueblos de Nuestra América (ALBA),en la que nos interesa destacar los acuerdos comerciales, llevados a cabo con el pueblo de Cuba, 2) La Comunidad Andina de Naciones (CAN, previamente Pacto Andino), que inició un proyecto de integración regional basada en la planificación industrial ${ }^{3}$.

Un dato importante es que hasta hoy día los acuerdos de integración, han estado dirigidos por lo Estados nacionales, que estimula el trabajo independiente de los pueblos originarios, ya que si bien es cierto se han logrado algunos logros importantes. Como un ejemplo, podemos citar en el "acta de instalación de la mesa de los pueblos andinos de la comunidad andina", que se llevó a cabo el 11 de mayo de 2002, reunidos en Urubamba, Cuzco - Perú, en donde los representantes de las organizaciones indígenas de Bolivia, Colombia, Ecuador, Perú y Venezuela, se reunieron para fortalecer sus lazos, por lo que recordaron que habían obtenido significativos avances en cuanto al reconocimiento político y jurídico, así como las iniciativas económicas

3 Consúltese la página electrónica: intranet.comunidadandina.org/Documentos/.../SGdi430. doc Fecha de consulta 21 de enero de 2010. 
destinadas a impulsar el crecimiento de las poblaciones andinas.

Ahora bien, es de suma importancia considerar los avances en cuanto al reconocimiento, sin embargo, todavía hoy las comunidades andinas siguen siendo las más golpeadas. Por lo que es importante que continúen por el mismo camino, pero confiamos en que la experiencia los conduzca hacia el trabajo independiente, esto es a no atenerse a pautas políticas establecidas por las instituciones mundiales y menos de las establecidas por sus respectivos países. Por lo que es preciso profundizar en los acuerdos, a partir de sus necesidades, exigencias y proyectos, con ello podrán cumplir una parte muy importante de los Acuerdos Supranacionales, la creación de un nuevo orden jurídico, en donde hay una "primacía del Derecho Comunitario" (Jaime Delgado, 2008, p. 185).

\section{El caso mexicano}

Así como en otras regiones de América Latina, los grupos originarios se están organizando para concretar un reconocimiento así como trato justo y diferenciado. En México, también se están llevando a cabo acciones similares, de ahí que el ejemplo más destacado continúe siendo el del Ejército Zapatista de Liberación Nacional.

Sin embargo, coincidimos con las opiniones las cuales señalan que para concretar sus objetivos, es necesario recuperar la tradición republicana legada por Roma y traída a la Nueva España por los hispanos, debido a que en dicho sistema de organización se ponía énfa- sis en la virtud de los ciudadanos "y la convicción de que hay un bien público más allá de los intereses de los particulares" (Fernando Escalante, 1998, p. 35). Por lo que lo público adquiere mayor importancia que lo privado.

En este orden de ideas, para atender los actos de consecuencias amplias, el público necesita formar arbitrios y medidas especiales, así la idea del "espacio público es la de un conjunto de mecanismos para tratar con los problemas colectivos, por lo cual lo público es, por así decirlo, una solución inevitable, casi espontánea, de los problemas que supone la coexistencia pacífica" (Fernando Escalante, 1998, p. 35).

Para concluir queremos exponer la situación en México, en donde el EZLN, exigió una representación más equitativa y una nueva reorganización federal que refleje el pluralismo cultural y promueva una descentralización política en beneficio de los poderes locales, principalmente municipales.

Desdichadamente, en México a pesar de que en el artículo $2^{\circ}$ de la Constitución se lee:

La nación tiene una composición pluricultural sustentada originalmente en sus pueblos indígenas que son aquellos que descienden de poblaciones que habitan en el territorio actual del país al iniciarse la colonización y que conservan sus propias instituciones sociales, económicas, culturales y políticas, o parte de ellas.

Inicio de artículo bastante benéfico. Infortunadamente en otro párrafo se lee: 
La federación, los estados y municipios, para promover la igualdad de oportunidades de los indígenas y eliminar cualquier práctica discriminatoria, establecerán las instituciones y determinarán las políticas necesarias para garantizar la vigencia de los derechos de los indígenas y el desarrollo integral de sus pueblos y comunidades, las cuales deberán ser diseñadas y operadas conjuntamente con ellos (Constitución Política de los Estados Unidos Mexicanos, México, 2005, p. 6).

De tal modo, como lo señaló Ambrosio Velasco en lugar de reconocer a los pueblos indígenas como sujetos de derecho público se los reconoce como entidades de "interés público" para la política de asistencia social.

Por lo que constitucionalmente en este artículo se debería leer:

La federación, los estados y municipios, para promover la igualdad de oportunidades de los indígenas y eliminar cualquier práctica discriminatoria, por lo que reconocen las normas propias de cada pueblo para la elección de autoridades y creación de instituciones, como sistemas políticos de gobierno. Por lo que serán capaces de decidir e interactuar con los gobiernos nacionales y establecer los Acuerdos de Integración Supranacionales pertinentes, para desarrollo cultural, político y económico.

Ahora, no somos tan ingenuos de pensar que con el simple hecho de que en la Constitución mexicana se les reconozca el derecho a erigir sus propias instituciones, bastará para solucionar sus problemas, ya que seguramente será necesario reelaborar otros artículos para que efectivamente puedan llevar a cabo sus planes. Claro además de que aparecerán los intereses particulares que tratarán de impedir que se lleve a cabo.

Sin embargo, somos de la opinión de que sólo a través de reconocer su derecho a la autodeterminación, es que podrán concretar sus proyectos de bienestar comunitario. Sobre todo, porqué en nuestro país ya hay ejemplos de ello, ya que no se debe olvidar la legislación de Oaxaca que ya permite las autonomías. Claro que debido al control político que el Estado ha ejercido sobre dichas poblaciones, ese sistema político no ha florecido. Pero lo que queremos enfatizar es que no es imposible.

\section{A manera de conclusiones}

El tema de la identidad constituye uno de los principales intereses de los seres humanos, esto es, encontrar las expresiones culturales y con ello el medio de subsistencia con las cuales las personas se sienten a gusto, así como el grupo o grupos de personas cuyo contacto proporcionan mayor alegría, incluyendo a la pareja adecuada, todo ello, de una u otra manera, guiado o sustentado por las condiciones culturales que históricamente se desarrollaron en el lugar donde nace el ser humano.

Sin embargo, en el caso de América Latina, se suscitó una conquista, la cual forzó al cambio de las prácticas y cosmovisión social, suscitándose así una controversia entre lo propio y lo impuesto, en lo cual lo impuesto his- 
tóricamente provocó en la población una concepción negativa de las propias creaciones, las cuales afortunadamente hoy son revaloradas destacándose su importancia.

De tal modo que, el problema de la identidad no es el que la población no se conozca, aunque amplios sectores desconozcan datos y procesos de su propia formación cultural, ya que la identidad se vive y reproduce en lo cotidiano, aunque esté mezclada con las imposiciones, ya que también éstas, actualmente, constituyen expresiones de lo propio. De tal modo que, más bien, no gusta o no satisface lo que se dice o conoce de la propia identidad, lo cual es distinto a indicar que se desconoce.

Por ello, revalorar la propia identidad, implica además de conocer la historia considerarse como ser huma- no pleno, al igual que las personas de otras naciones, en condiciones de vida más difíciles, es cierto, pero que por lo mismo, se deben organizar y construir propuestas de un mundo alternativo, en el que la dominación, el egoísmo, la explotación y el racialismo, entre otros males, dejen su lugar a tratos de convivencia pacífica, a la tolerancia y a la comprensión.

Para ello es imprescindible que las poblaciones participen en la construcción del sistema político que requieren para vivir. Por ello, en este trabajo se abordó la importancia del derecho a la autodeterminación, como lo es el caso de las poblaciones descendientes de las naciones originarias. Ello implica la aceptación de la diversidad y la práctica de la interculturalidad. 


\section{BIBLIOGRAFÍA}

Constitución Política de los Estados Unidos Mexicanos. México: IFE, 2005.

Delgado Rojas, J. G. (2008). "Integración y supranacionalidad en América Latina”, en Rodrigo Páez y Mario Vázquez (coords.), Integración latinoamericana, Raíces y perspectivas. México: EON - UNAM - CIALC, Col. Miradas del Centauro.

Díaz Polanco, H. (1988). “Las minorías étnicas como categoría política en la cuestión regional”, en La cuestión étnico-nacional en América Latina. México: Fontamara.

Escalante Gonzalbo, F. (1998). Ciudadanos imaginarios, memoria de los afanes y desventuras de la virtud y apología del vicio triunfante en la República mexicana: Tratado de moral pública, 3a reimp. México: El Colegio de México.

Renan, E. (1987). ¿Qué es una nación? Madrid: Alianza.

Zea, L. (1976). El pensamiento latinoamericano, 3a edición. Barcelona: Ariel, Col. Demos.

\section{Página electrónica}

intranet.comunidadandina.org/Documentos/.../SGdi430.doc Fecha de consulta 21 de enero de 2010. 